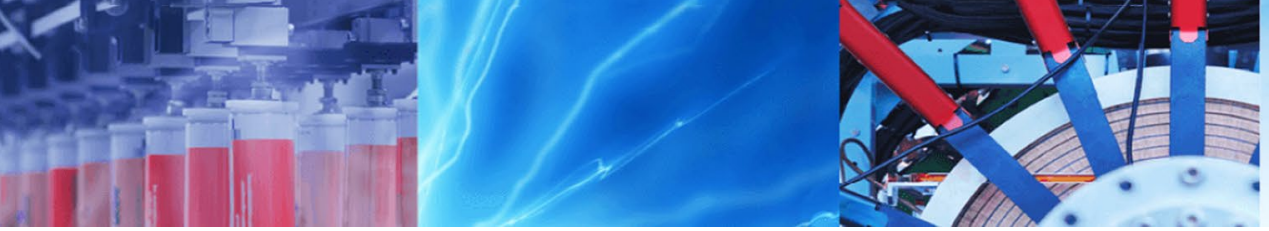

Research Article

\title{
A 12-sector space vector switching table for parallel-connecting to dual induction motors fed by matrix convertor based on direct torque control
}

\author{
Mahdi Jafari ${ }^{1} \cdot$ Karim Abbaszadeh ${ }^{2} \cdot$ Mustafa Mohammadian ${ }^{3}$
}

Received: 10 January 2020 / Accepted: 10 August 2021

Published online: 30 October 2021

(c) The Author(s) 2021 OPEN

\begin{abstract}
The present study proposes an improved switching table of direct torque control (DTC) for two parallel connection induction motors fed by matrix convertor. This method is based on the mean control strategy and allows the use of all switching states of matrix convertor. These functions represent the relationship between the change rates of the torque, flux, and input power factor of motors and the output voltage vector and input current vector of the matrix convertor. The effect of matrix convertor switching states on the change rate of the torque, flux, and input power factor is established by averaging approach and is done in the four improved switching tables. Finally, the optimal switching state is chosen from the switching tables. The results show that overshoot of motors speed to following reference input is $1 \%$ of reference speed less than conventional methods and also, oscillation of motors torque is less than conventional methods. Numerical results show the effectiveness of the proposed approach and prove its reliability for industrial uses.
\end{abstract}

\section{Article Highlights}

In summary, the highlight of this research is the simultaneous control of torque and speed of two electric motors by an inverter. In such a way that even in different conditions of motors load, speed and torque follow the reference values well. Also, using the advantages of DTC algorithm and applying it to use matrix convertor are the highlights of this research

Keywords Matrix convertor · Single-inverter multi-motor drive · Direct torque control

\section{Introduction}

Developments in power electronic equipment and microprocessors during the last three decades have led to improvements in the methods of controlling electrical machines. Control of several motors simultaneously are used in many industrial uses, such as paper or steel rolling mills and electrical systems of railroad [1]. The use of single inverter to control several motors is preferred in the cases that precised speed synchronization of motors is not important. Altough, complexity of system increases because the use of single inverter instead of mulitple inverters but it reduces the costs, weight, required space, and the number of switches. This system

Karim Abbaszadeh, abbaszadeh@kntu.ac.ir | ${ }^{1}$ Department of Electrical Engineering, Faculty of Electrical Engineering, Science and Research Branch, Islamic Azad University, Tehran, Iran. ${ }^{2}$ Department of Electrical Engineering, Faculty of Electrical Engineering, Khajeh Nassir-Al-Deen Toosi University of Technology, Tehran, Iran. ${ }^{3}$ Department of Electrical Engineering, Faculty of Electrical Engineering, Tarbiat Modares University, Tehran, Iran. 
increases reliability compared to those with mechanical components such as gears and line shafts [2]. The parallel and series connected motors can be separately controlled on the basis of the number of stator phases. It means that the multiphase motors can be connected in series, except three-phase motors [3].

The most limitations in single inverter of dual motor drives are the following: (1) when the single voltage vector is applied to both motors, stator flux is instantantly put in the same direction, and (2) when unbalanced load condition takes place, the speed of the motors does not reach the desired values $[4,5]$. The Control of dual motors using multiple-leg inverters has recently garnered much interest. For instance, the vector control method [6] uses a fourleg inverter while the approach proposed in $[7,8]$, uses a five-leg inverter. Such inverters can feed the two motors with different voltage vectors. However, if the number of motors is increased, the number of switches also must be increased [9]. Also another convertors well known the matrix convertors can be used for feeding a large number of voltage vectors. Some of these vectors, called active vectors, have constant direction but variable amplitude; however, some others, called rotation vectors [10], have constant amplitude but variable direction (Table 1). The use of both groups of vectors in single inverter dual motors creates a continuous vector space. The two main properties of the matrix convertors are its capability for generating sinusoidal input-output voltage and current and to adjust input power factor $[11,12]$. The matrix convertors are preferred for extreme temperatures and critical volume-weight [13]. The control and the modulation are two major subjects in the single inverter dual motors. The present control strategies are basically of two main types: (1)The master-slave pattern, which is used in the same
Table 1 The vector space of a $3 \times 3$ matrix convertor

\begin{tabular}{|c|c|c|c|c|c|c|c|}
\hline \multirow[t]{2}{*}{ State } & \multicolumn{3}{|c|}{ Activated switches } & \multicolumn{2}{|c|}{ Voltage-vector values } & \multicolumn{2}{|c|}{ Current-vector values } \\
\hline & & & & $\mathrm{V}_{\mathrm{o}}$ & ${ }_{0} a$ & $\mathrm{I}_{\text {in }}$ & $\beta$ \\
\hline+1 & $\mathrm{~S}_{\mathrm{Aa}}$ & $\mathrm{S}_{\mathrm{Bb}}$ & $\mathrm{S}_{\mathrm{BC}}$ & $2 / 3 V_{A B}$ & 0 & $2 / \sqrt{3} i_{a}$ & $-\pi / 6$ \\
\hline-1 & $\mathrm{~S}_{\mathrm{Ba}}$ & $\mathrm{S}_{\mathrm{Ab}}$ & $\mathrm{S}_{\mathrm{AC}}$ & $-2 / 3 V_{A B}$ & 0 & $2 / \sqrt{3} i_{a}-$ & $-\pi / 6$ \\
\hline+2 & $\mathrm{~S}_{\mathrm{Ba}}$ & $\mathrm{S}_{\mathrm{Ab}}$ & $\mathrm{S}_{\mathrm{Cc}}$ & $2 / 3 V_{B C}$ & 0 & $2 / \sqrt{3} i_{a}$ & $\pi / 2$ \\
\hline-2 & $\mathrm{~S}_{\mathrm{Ca}}$ & $\mathrm{S}_{\mathrm{Bb}}$ & $\mathrm{S}_{\mathrm{BC}}$ & $-2 / 3 V_{B C}$ & 0 & $2 / \sqrt{3} i_{a^{-}}$ & $\pi / 2$ \\
\hline $3+$ & $\mathrm{S}_{\mathrm{Ca}}$ & $\mathrm{S}_{\mathrm{Ab}}$ & $\mathrm{S}_{\mathrm{AC}}$ & $2 / 3 V_{C A}$ & 0 & $2 / \sqrt{3} i_{a}$ & $7 \pi / 6$ \\
\hline $3-$ & $\mathrm{S}_{\mathrm{Aa}}$ & $\mathrm{S}_{\mathrm{Cb}}$ & $\mathrm{S}_{\mathrm{Cc}}$ & $-2 / 3 V_{C A}$ & 0 & $2 / \sqrt{3} i_{a}-$ & $7 \pi / 6$ \\
\hline+4 & $\mathrm{~S}_{\mathrm{Ba}}$ & $\mathrm{S}_{\mathrm{Ab}}$ & $\mathrm{S}_{\mathrm{BC}}$ & $2 / 3 \mathrm{~V}_{\mathrm{AB}}$ & $2 \pi / 3$ & $2 / \sqrt{3} i_{b}$ & $-\pi / 6$ \\
\hline-4 & $\mathrm{~S}_{\mathrm{Aa}}$ & $\mathrm{S}_{\mathrm{Bb}}$ & $\mathrm{S}_{\mathrm{Ac}}$ & $-2 / 3 V_{A B}$ & $2 \pi / 3$ & $2 / \sqrt{3} i_{b^{-}}$ & $-\pi / 6$ \\
\hline $5+$ & $\mathrm{S}_{\mathrm{Ca}}$ & $\mathrm{S}_{\mathrm{Bb}}$ & $\mathrm{S}_{\mathrm{Cc}}$ & $2 / 3 V_{B C}$ & $2 \pi / 3$ & $2 / \sqrt{3} i_{b}$ & $\pi / 2$ \\
\hline-5 & $\mathrm{~S}_{\mathrm{Ba}}$ & $\mathrm{S}_{\mathrm{Ca}}$ & $\mathrm{S}_{\mathrm{BC}}$ & $-2 / 3 V_{B C}$ & $2 \pi / 3$ & $2 / \sqrt{3} i_{b^{-}}$ & $\pi / 2$ \\
\hline+6 & $\mathrm{~S}_{\mathrm{Aa}}$ & $\mathrm{S}_{\mathrm{Cb}}$ & $\mathrm{S}_{\mathrm{AC}}$ & $2 / 3 V_{C A}$ & $2 \pi / 3$ & $2 / \sqrt{3} i_{b}$ & $7 \pi / 6$ \\
\hline-6 & $\mathrm{~S}_{\mathrm{Ca}}$ & $\mathrm{S}_{\mathrm{Cb}}$ & $\mathrm{S}_{\mathrm{Cc}}$ & $-2 / 3 V_{C A}$ & $2 \pi / 3$ & $2 / \sqrt{3} i_{b}-$ & $7 \pi / 6$ \\
\hline+7 & $\mathrm{~S}_{\mathrm{Ba}}$ & $\mathrm{S}_{\mathrm{Bb}}$ & $\mathrm{S}_{\mathrm{Ac}}$ & $2 / 3 V_{A B}$ & $4 \pi / 3$ & $2 / \sqrt{3} i_{c}$ & $-\pi / 6$ \\
\hline-7 & $\mathrm{~S}_{\mathrm{Aa}}$ & $\mathrm{S}_{\mathrm{Ab}}$ & $\mathrm{S}_{\mathrm{BC}}$ & $-2 / 3 V_{A B}$ & $4 \pi / 3$ & $2 / \sqrt{3} i_{c}$ & $-\pi / 6$ \\
\hline+8 & $\mathrm{~S}_{\mathrm{Ca}}$ & $\mathrm{S}_{\mathrm{Cb}}$ & $\mathrm{S}_{\mathrm{BC}}$ & $2 / 3 V_{B C}$ & $4 \pi / 3$ & $2 / \sqrt{3} i_{c}$ & $\pi / 2$ \\
\hline-8 & $\mathrm{~S}_{\mathrm{Ba}}$ & $\mathrm{S}_{\mathrm{Bb}}$ & $\mathrm{S}_{\mathrm{Cc}}$ & $-2 / 3 V_{B C}$ & $4 \pi / 3$ & $2 / \sqrt{3} i_{c}$ & $\pi / 2$ \\
\hline+9 & $\mathrm{~S}_{\mathrm{Aa}}$ & $\mathrm{S}_{\mathrm{Ab}}$ & $\mathrm{S}_{\mathrm{Cc}}$ & $2 / 3 V_{C A}$ & $4 \pi / 3$ & $2 / \sqrt{3} i_{c}$ & $7 \pi / 6$ \\
\hline-9 & $\mathrm{~S}_{\mathrm{Ca}}$ & $\mathrm{S}_{\mathrm{Cb}}$ & $\mathrm{S}_{\mathrm{AC}}$ & $-2 / 3 V_{C A}$ & $4 \pi / 3$ & $2 / \sqrt{3} i_{c}$ & $7 \pi / 6$ \\
\hline+10 & $\mathrm{~S}_{\mathrm{Aa}}$ & $\mathrm{S}_{\mathrm{Bb}}$ & $\mathrm{S}_{\mathrm{Cc}}$ & $\mathrm{V}_{\text {in }}$ & in $a$ & $\mathrm{I}_{\mathrm{o}}$ & ${ }_{0} \beta$ \\
\hline-10 & $\mathrm{~S}_{\mathrm{Aa}}$ & $\mathrm{S}_{\mathrm{BC}}$ & $\mathrm{S}_{\mathrm{Cb}}$ & $\mathrm{V}_{\text {in }}$ & ${ }_{\text {in }}{ }^{-}$ & $\mathrm{I}_{\mathrm{o}}$ & ${ }_{0} \beta-$ \\
\hline+11 & $\mathrm{~S}_{\mathrm{Ab}}$ & $\mathrm{S}_{\mathrm{BC}}$ & $\mathrm{S}_{\mathrm{Ca}}$ & $\mathrm{V}_{\text {in }}$ & $\alpha_{i n}-2 \pi / 3$ & $\mathrm{I}_{\mathrm{o}}$ & $\beta_{o}+2 \pi / 3$ \\
\hline-11 & $\mathrm{~S}_{\mathrm{Ab}}$ & $\mathrm{S}_{\mathrm{Ca}}$ & $\mathrm{S}_{\mathrm{Cc}}$ & $V_{\text {in }}$ & $-\alpha_{i n}+2 \pi / 3$ & $\mathrm{I}_{\mathrm{o}}$ & $-\beta_{0}+2 \pi / 3$ \\
\hline+12 & $\mathrm{~S}_{\mathrm{AC}}$ & $\mathrm{S}_{\mathrm{Ba}}$ & $\mathrm{S}_{\mathrm{Cb}}$ & $V_{\text {in }}$ & $\alpha_{i n}+2 \pi / 3$ & $\mathrm{I}_{\mathrm{o}}$ & $\beta_{o}-2 \pi / 3$ \\
\hline-12 & $\mathrm{~S}_{\mathrm{AC}}$ & $\mathrm{S}_{\mathrm{Bb}}$ & $\mathrm{S}_{\mathrm{Ca}}$ & $\mathrm{V}_{\text {in }}$ & $-\alpha_{i n}-2 \pi / 3$ & $\mathrm{I}_{\mathrm{o}}$ & $-\beta_{o}-2 \pi / 3$ \\
\hline $0_{A}$ & $\mathrm{~S}_{\mathrm{Aa}}$ & $\mathrm{S}_{\mathrm{Ab}}$ & $\mathrm{S}_{\mathrm{AC}}$ & 0 & - & 0 & - \\
\hline $0_{B}$ & $\mathrm{~S}_{\mathrm{Ba}}$ & $\mathrm{S}_{\mathrm{Bb}}$ & $\mathrm{S}_{\mathrm{BC}}$ & 0 & - & 0 & - \\
\hline $0_{C}$ & $\mathrm{~S}_{\mathrm{Ca}}$ & $\mathrm{S}_{\mathrm{Cb}}$ & $\mathrm{S}_{\mathrm{Cc}}$ & 0 & - & 0 & - \\
\hline
\end{tabular}


machines. Here, to ensure that the stator flux keeps within its nominal range, the motor with the greater amplitude of the stator flux is set as the master, and the behavior of the slave motor is not checked. However, a restriction of this arrangement is that the behavior of the slave motor may not be acceptable in some cases $[2,4]$. (2)The mean control pattern, where the average and differential values of the speed and current of the motors are calculated. The main disadvantage of this pattern is that the stator flux of either motor may go beyond the reference value [4]. Moreover, a third pattern would be to mix the mentioned patterns [2].

Each of the mentioned patterns can be implemented through the use of either vector control or direct torque control (DTC) methods. For example, a sensorless vector control method was propounded by [14] based on the mean control pattern and the sum of the torque values of two induction motors controlled by a three-leg inverter. By [15] made a comparison between the P controller and the $\mathrm{PI}$ controller in terms of their effect on the torque control loop. In addition, in $[1,16]$ propounded the weighted vector control method for improving the speed function and startup conditions of a dual-motor drive and considered differences in torque values. A straightforward method presented by [17] improved controlling of single inverter in drives of dual induction motors.

The use of the DTC method for controlling single inverter in drives of dual motors has been less studied compared to the vector control method. By [18] proposed a method according to the master-slave pattern and based on the classical DTC method to control a system consisting of two permanent magnet synchronous motors fed by a three-leg inverter. The DTC approach allows easier torque control and a fast dynamic response, that does not need the transformation of rotary coordinates, and is independent of motor parameters [19]. However, the DTC method has more torque and current ripple than does the vector control approach [20]. The previous researchs indicate that using the master-slave pattern implemented via the DTC approach achieves the better results than does the vector control method. The opposite is true of the mean control pattern [2]. In the conventional DTC method, the vector space is divided to six sectors of $60^{\circ}$ which results in eight voltage vectors. Considering the resultant discrete voltage space, it is impossible to accurately produce the voltage vector required to generate flux and torque [21]. To solve this problem, different approaches have been propounded which increased complexity of the DTC approach [10]. One of them is space vector modulation (SVM) [22], that provides continuous vector space for voltage modulation [23]. The SVM method works by removing the hystersis blocks and the lookup table, but it increases the complexity of computations. Also there is another configuration of DTC based methods which enhance the lookup table in order to select the optimal switching state. These methods result acceptable outputs and at the same time, it provides simplicity of control $[21,24]$. The matrix convertor can produce 27 voltage vectors that creates a continuous voltage space. In the conventional DTC approach, only 18 vectors have a constant direction, and this implies the loss of the advantages of the matrix convertor [10]. To solve this problem, in [25] developed a modified DTC method, in which the circular vector space is divided up into twelve sectors of $30^{\circ}$. This modified technique investigates the effect of all the voltage vectors of the matrix convertor on the changes in flux, torque, and input power factor.

The purpose of the study reported here is threefold: (1) to introduce a novel drive system with a matrix convertor for two parallel-connected induction motors through the enhanced switching tables. Also the proposed control method is explianed. (2) to lower the torque ripple more than does the conventional DTC; and (3) to maintain the stability of motor speed under unbalanced load circumstances. The remainder of the paper is as follows. In Sect. 2, the proposed control method is delineated. Section 3 presents and discusses the simulation results. Finally, conclusions are given in Sect. 4.

\section{Materials and methods}

\subsection{Modeling of dual induction motors in the proposed method}

If the voltage drop of the stator resistance is disregarded, the flux equation of induction motors will be as follows:

$\overrightarrow{\Delta \psi_{s}}=\overrightarrow{V_{s}} \cdot \Delta t$

The radial and tangential components of the stator voltage vector alter the amplitude and angle of the stator flux vector, respectively. These components are expressed in a synchronous reference frame as follows [10]:

$V_{d}^{s}=V_{\alpha} \cos \theta+V_{\beta} \sin \theta$

$V_{q}^{s}=-V_{\alpha} \sin \theta+V_{\beta} \cos \theta$

In the single inverter dual motor drives, a same voltage vector is applied to both motors simultaneously. In this case, variations in the amplitude of the stator flux for each motor are described as follows:

$\Delta\left|\vec{\psi}_{s 1}\right|=V_{d}^{s} \cdot \Delta t$ 
$\Delta\left|\vec{\psi}_{s 2}\right|=V_{d}^{s} \cdot \Delta t$

By applying Eqs. (1) to (5) to each motor and using the mean control pattern, the flux average and torque average are expressed as follows:

$\frac{\left|\vec{\psi}_{s 1}\right|+\left|\vec{\psi}_{s 2}\right|}{2}=\left|\overline{\psi_{s}}\right|$

$\frac{T_{e 1}+T_{e 2}}{2}=\bar{T}_{e}$

By applying Eqs. (4) and (5) to each motor and considering Eq. (2), the effect of the radial component of the applied voltage vector on the variations in the average flux of stator in the interval $\left[t_{1}, t_{2}\right]$ can be described as follows:

$\Delta\left|\bar{\psi}_{s}\right|=\left|\bar{\psi}_{s t 2}\right|-\left|\bar{\psi}_{s t 1}\right| \cong \bar{V}_{d} \cdot \Delta t \Rightarrow \frac{d\left|\overrightarrow{\bar{\psi}}_{s}\right|}{d t}=\bar{V}_{d}=v_{\alpha} \cos \theta+v_{\beta} \sin \theta$

The torque of the induction motor can be expressed using Eq. (9) [10]:

$T_{e}=\frac{3}{2} \cdot \frac{P}{2} \cdot \frac{L_{m}}{\sigma \cdot L_{s} \cdot L_{r}} \cdot\left|\vec{\psi}_{r}\right| \cdot\left|\vec{\psi}_{s}\right| \cdot \sin \gamma$

where $\sigma$ and $\gamma$ are leakage factor and load angle, respectively.

By substituting Eqs. 6 and 7 in Eq. 9 for the single inverter dual motor drives, average torque will be expressed as below:

$\bar{T}_{e}=\frac{3}{2} \cdot \frac{P}{2} \cdot \frac{L_{m}}{\sigma \cdot L_{s} \cdot L_{r}} \cdot\left|\overrightarrow{\bar{\psi}}_{r}\right| \cdot\left|\overrightarrow{\bar{\psi}}_{s}\right| \cdot \sin \gamma$

Torque changes resulting from the applied $\vec{V}_{s}$ are as follows:

$\Delta \bar{T}_{e}=k \cdot\left|\overrightarrow{\bar{\psi}}_{r}\right| \cdot\left(\frac{d\left|\overrightarrow{\bar{\psi}}_{s}\right|}{d t} \cdot \sin \gamma+\frac{d \gamma}{d t} \cdot \cos \gamma \cdot\left|\overrightarrow{\bar{\psi}}_{s}\right|\right) \cdot \Delta t$

where $\mathrm{K}$ is a constant defined as Eq. (12) below:

$k=\frac{3}{2} \cdot \frac{P}{2} \cdot \frac{L_{m}}{\sigma \cdot L_{s} \cdot L_{r}}$

Hence:

$\Delta \gamma=\Delta \theta-\Delta \zeta$

where $\Delta \theta$ and $\Delta \zeta$ are the change in the angles of $\vec{\psi}_{s}$ and $\vec{\psi}_{r}$, respectively, that results from the application of the voltage vector.

The following equation indicates the change in the amplitude of $\vec{\psi}_{s}$ :
$\Delta\left|\overrightarrow{\bar{\psi}}_{s t}\right|=\Delta \theta \cdot\left|\overrightarrow{\bar{\psi}}_{s 1}\right| \cong V_{q} \cdot \Delta t$

Therefore:

$\frac{d \theta}{d t}=\frac{V_{q}}{\left|\overrightarrow{\bar{\psi}}_{s 1}\right|}$

Given that the rotor flux rotates at synchronous speed,

$\Delta \zeta=\omega_{s} \cdot \Delta t \Rightarrow \frac{d \zeta}{d t}=\omega_{s}$

Substituting (3), (15), and (16) in (13) results:

$\frac{d \gamma}{d t}=\frac{d \theta}{d t}-\frac{d \zeta}{d t}=\frac{-V_{\alpha} \sin \theta+V_{\beta} \cos \theta}{\left|\vec{\psi}_{s 1}\right|}-\omega_{s}$

Also, if (8) and (17) are substituted in (11), the change in the average torque is expressed as follows:

$\Delta \bar{T}_{e}=k \cdot\left|\vec{\psi}_{r}\right| \cdot\left(v_{d} \cdot \sin \gamma+\left(v_{q}-\omega_{s} \cdot\left|\vec{\psi}_{s}\right|\right) \cdot \cos \gamma\right) \cdot \Delta t$

The flux evaluation function $(\lambda)$, torque evaluation function $(\tau)$, and the back-EMF evaluation function $(e)$ of the matrix convertor are defined as follows [10]:

$\lambda=\frac{V_{q}}{2 / \sqrt{3} V_{\text {in }}}$

$\tau=\frac{V_{d}}{2 / \sqrt{3} V_{\text {in }}}$

$e=\frac{\omega_{s} \cdot\left|\vec{\psi}_{s 1}\right|}{2 / \sqrt{3} V_{i n}}$

where $V_{\text {in }}$ is the amplitude of the input voltage vector. By substituting (19), (20), and (21) in (8) and (18), the rate of the effect of each voltage vector on the change of the average torque and the average flux are estimated as below:

$\frac{d}{d t} \bar{T}_{e} \propto \tau+\lambda-e$

$\frac{d}{d t}\left|\overrightarrow{\bar{\psi}}_{s 1}\right| \propto \lambda$

The $d$ and $q$ voltage components of the matrix convertor are substituted in (19) and (20). The $\tau$ functions and the $\lambda$ functions are presented in Table 2 . Results indicate that these $\tau$ and $\lambda$ functions are dependent on the angle of the input voltage and the angle of the average flux vector, 
Table 2 Evaluation functions of torque, flux and input power factor

\begin{tabular}{|c|c|c|c|}
\hline \multirow[t]{2}{*}{ MC state } & \multicolumn{3}{|c|}{ Evaluation functions of torque, flux and input power factor } \\
\hline & $\tau$ & $\lambda$ & $\eta$ \\
\hline+1 & $-\cos \left(\alpha_{i}+\pi / 6\right) \sin \theta_{s}$ & $\cos \left(\alpha_{i}+\pi / 6\right) \cos \theta_{s}$ & $-\sin \left(\alpha_{i}+\pi / 6\right) \cos \beta_{o}$ \\
\hline-1 & $\cos \left(\alpha_{i}+\pi / 6\right) \sin \theta_{s}$ & $-\cos \left(\alpha_{i}+\pi / 6\right) \cos \theta_{s}$ & $\sin \left(\alpha_{i}+\pi / 6\right) \sin \beta_{o}$ \\
\hline+2 & $-\cos \left(\alpha_{i}-\pi / 2\right) \sin \theta_{s}$ & $\cos \left(\alpha_{i}-\pi / 2\right) \cos \theta_{s}$ & $-\sin \left(\alpha_{i}-\pi / 2\right) \cos \beta_{o}$ \\
\hline-2 & $\cos \left(\alpha_{i}-\pi / 2\right) \sin \theta_{s}$ & $-\cos \left(\alpha_{i}-\pi / 2\right) \cos \theta_{s}$ & $\sin \left(\alpha_{i}-\pi / 2\right) \cos \beta_{o}$ \\
\hline $3+$ & $-\cos \left(\alpha_{i}+5 \pi / 6\right) \sin \theta_{s}$ & $\cos \left(\alpha_{i}+5 \pi / 6\right) \cos \theta_{s}$ & $-\sin \left(\alpha_{i}-7 \pi / 6\right) \cos \beta_{o}$ \\
\hline $3-$ & $\cos \left(\alpha_{i}+5 \pi / 6\right) \sin \theta_{s}$ & $-\cos \left(\alpha_{i}+5 \pi / 6\right) \cos \theta_{s}$ & $\sin \left(\alpha_{i}-7 \pi / 6\right) \cos \beta_{o}$ \\
\hline+4 & $-\cos \left(\alpha_{i}+\pi / 6\right) \sin \left(\theta_{s}-2 \pi / 3\right)$ & $\cos \left(\alpha_{i}+\pi / 6\right) \cos \left(\theta_{s}-2 \pi / 3\right)$ & $-\sin \left(\alpha_{i}+\pi / 6\right) \cos (\beta o-2 \pi / 3)$ \\
\hline-4 & $\cos \left(\alpha_{i}+\pi / 6\right) \sin \left(\theta_{s}-2 \pi / 3\right)$ & $-\cos \left(\alpha_{i}+\pi / 6\right) \cos \left(\theta_{s}-2 \pi / 3\right)$ & $\sin \left(\alpha_{i}+\pi / 6\right) \cos (\beta o-2 \pi / 3)$ \\
\hline $5+$ & $-\cos \left(\alpha_{i}-\pi / 2\right) \sin \left(\theta_{s}-2 \pi / 3\right)$ & $\cos \left(\alpha_{i}-\pi / 2\right) \cos \left(\theta_{s}-2 \pi / 3\right)$ & $-\sin \left(\alpha_{i}-\pi / 2\right) \cos (\beta o-2 \pi / 3)$ \\
\hline-5 & $\cos \left(\alpha_{i}-\pi / 2\right) \sin \left(\theta_{s}-2 \pi / 3\right)$ & $-\cos \left(\alpha_{i}-\pi / 2\right) \cos \left(\theta_{s}-2 \pi / 3\right)$ & $\sin \left(\alpha_{i}-\pi / 2\right) \cos (\beta o-2 \pi / 3)$ \\
\hline+6 & $-\cos \left(\alpha_{i}+5 \pi / 6\right) \sin \left(\theta_{s}-2 \pi / 3\right)$ & $\cos \left(\alpha_{i}+5 \pi / 6\right) \cos \left(\theta_{s}-2 \pi / 3\right)$ & $-\sin \left(\alpha_{i}-7 \pi / 6\right) \cos (\beta o-2 \pi / 3)$ \\
\hline-6 & $\cos \left(\alpha_{i}+5 \pi / 6\right) \sin \left(\theta_{s}-2 \pi / 3\right)$ & $-\cos \left(\alpha_{i}+5 \pi / 6\right) \cos \left(\theta_{s}-2 \pi / 3\right)$ & $\sin \left(\alpha_{i}-7 \pi / 6\right) \cos (\beta o-2 \pi / 3)$ \\
\hline+7 & $-\cos \left(\alpha_{i}+\pi / 6\right) \sin \left(\theta_{s}-4 \pi / 3\right)$ & $\cos \left(\alpha_{i}+\pi / 6\right) \cos \left(\theta_{s}-4 \pi / 3\right)$ & $-\sin \left(\alpha_{i}+\pi / 6\right) \cos (\beta o+2 \pi / 3)$ \\
\hline-7 & $\cos \left(\alpha_{i}+\pi / 6\right) \sin \left(\theta_{s}-4 \pi / 3\right)$ & $-\cos \left(\alpha_{i}+\pi / 6\right) \cos \left(\theta_{s}-4 \pi / 3\right)$ & $\sin \left(\alpha_{i}+\pi / 6\right) \cos (\beta o+2 \pi / 3)$ \\
\hline+8 & $-\cos \left(\alpha_{i}-\pi / 2\right) \sin \left(\theta_{s}-4 \pi / 3\right)$ & $\cos \left(\alpha_{i}-\pi / 2\right) \cos \left(\theta_{s}-4 \pi / 3\right)$ & $-\sin \left(\alpha_{i}-\pi / 2\right) \cos (\beta o+2 \pi / 3)$ \\
\hline-8 & $\cos \left(\alpha_{i}-\pi / 2\right) \sin \left(\theta_{s}-4 \pi / 3\right)$ & $-\cos \left(\alpha_{i}-\pi / 2\right) \cos \left(\theta_{s}-4 \pi / 3\right)$ & $\sin \left(\alpha_{i}-\pi / 2\right) \cos (\beta o+2 \pi / 3)$ \\
\hline+9 & $-\cos \left(\alpha_{i}+5 \pi / 6\right) \sin \left(\theta_{s}-4 \pi / 3\right)$ & $\cos \left(\alpha_{i}+5 \pi / 6\right) \cos \left(\theta_{s}-4 \pi / 3\right)$ & $-\sin \left(\alpha_{i}-7 \pi / 6\right) \cos (\beta o+2 \pi / 3)$ \\
\hline-9 & $\cos \left(\alpha_{i}+5 \pi / 6\right) \sin \left(\theta_{s}-4 \pi / 3\right)$ & $-\cos \left(\alpha_{i}+5 \pi / 6\right) \cos \left(\theta_{s}-4 \pi / 3\right)$ & $\sin \left(\alpha_{i}-7 \pi / 6\right) \cos (\beta o+2 \pi / 3)$ \\
\hline+10 & $-\sqrt{3} / 2 \sin \left(\theta_{s}-\alpha_{i}\right)$ & $\sqrt{3} / 2 \cos \left(\theta_{s}-\alpha_{i}\right)$ & $-\sqrt{3} / 2 \sin \left(\alpha_{i}-\beta o\right)$ \\
\hline-10 & $\sqrt{3} / 2 \sin \left(\theta_{s}-\alpha_{i}\right)$ & $-\sqrt{3} / 2 \cos \left(\theta_{s}-\alpha_{i}\right)$ & $-\sqrt{3} / 2 \sin \left(\alpha_{i}+\beta o\right)$ \\
\hline+11 & $-\sqrt{3} / 2 \sin \left(\theta_{s}-\alpha_{i}+2 \pi / 3\right)$ & $\sqrt{3} / 2 \cos \left(\theta_{s}-\alpha_{i}+2 \pi / 3\right)$ & $-\sqrt{3} / 2 \sin \left(\alpha_{i}-\beta o-2 \pi / 3\right)$ \\
\hline-11 & $-\sqrt{3} / 2 \sin \left(\theta_{s}+\alpha_{i}-2 \pi / 3\right)$ & $\sqrt{3} / 2 \cos \left(\theta_{s}+\alpha_{i}-2 \pi / 3\right)$ & $-\sqrt{3} / 2 \sin \left(\alpha_{i}+\beta o-2 \pi / 3\right)$ \\
\hline+12 & $-\sqrt{3} / 2 \sin \left(\theta_{s}-\alpha_{i}-2 \pi / 3\right)$ & $\sqrt{3} / 2 \cos \left(\theta_{s}-\alpha_{i}-2 \pi / 3\right)$ & $-\sqrt{3} / 2 \sin \left(\alpha_{i}-\beta o+2 \pi / 3\right)$ \\
\hline-12 & $-\sqrt{3} / 2 \sin \left(\theta_{s}+\alpha_{i}+2 \pi / 3\right)$ & $\sqrt{3} / 2 \cos \left(\theta_{s}+\alpha_{i}+2 \pi / 3\right)$ & $-\sqrt{3} / 2 \sin \left(\alpha_{i}+\beta o+2 \pi / 3\right)$ \\
\hline $0_{A}$ & 0 & 0 & 0 \\
\hline $0_{B}$ & 0 & 0 & 0 \\
\hline $0_{C}$ & 0 & 0 & 0 \\
\hline
\end{tabular}

respectively. The input reactive power and input current vector can be used to obtain the evaluation function of input power factor (Eq. (24)). The $\eta$ functions of all voltage vectors of the matrix convertor are given in Table 2 .

$\eta=\frac{I_{q}}{2 / \sqrt{3} I_{i n}}$

where $I_{\text {in }}$ is the amplitude of the input current vector.

As it can be seen in Table 2, the evaluation functions ( $\eta$ ) are the functions of the angle of the input current and the angle of the voltage vector, respectively.

The relationship between $\eta$ and the input reactive power of single inverter dual motor can be expressed as follows [10]; $\frac{d}{d t} Q \propto \eta$

In order to extract the unit input power factor, input reactive power should be kept close to zero. Evaluation functions are proportional to the rate of the changes in torque, flux, and input reactive power.

\subsection{Enhanced switching table of matrix convertor}

According to Table 2, it is seen that the evaluation functions are dependent to $\theta_{s}$ and $\alpha_{i}$. The area between 0 and $2 \pi$ is divided into 12 sectors of 30 degrees and the mean change rate of every evaluation functions, based on the changes of $\theta_{s}$ and $\alpha_{i}$ is calculated in each sector that called impact factor. As it mentioned, the variation of impact 
Table 3 Impact factor of torque and flux for constant vectors of matrix convertor

\begin{tabular}{|c|c|c|c|c|c|c|c|c|c|c|c|c|c|c|c|}
\hline & & & & \multicolumn{12}{|c|}{ Stator flux sectors $n_{\theta}$} \\
\hline \multirow{3}{*}{$\mathcal{R}_{\lambda}$} & +3 & +2 & +1 & 4 & 5 & 6 & 7 & 8 & 9 & 10 & 11 & 12 & 1 & 2 & 3 \\
\hline & +6 & +5 & +4 & 8 & 9 & 10 & 11 & 12 & 1 & 2 & 3 & 4 & 5 & 6 & 7 \\
\hline & +9 & +8 & +7 & 12 & 1 & 2 & 3 & 4 & 5 & 6 & 7 & 8 & 9 & 10 & 11 \\
\hline \multirow{12}{*}{ 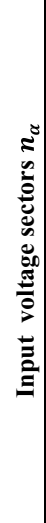 } & 8 & 4 & 12 & -3 & -6 & -9 & -9 & -6 & -3 & 3 & 6 & 9 & 9 & 6 & 3 \\
\hline & 7 & 3 & 11 & -3 & -6 & -9 & -9 & -6 & -3 & 3 & 6 & 9 & 9 & 6 & 3 \\
\hline & 6 & 2 & 10 & -2 & -5 & -6 & -6 & -5 & -2 & 2 & 5 & 6 & 6 & 5 & 2 \\
\hline & 5 & 1 & 9 & -1 & -2 & -3 & -3 & -2 & -1 & 1 & 2 & 3 & 3 & 2 & 1 \\
\hline & 4 & 12 & 8 & 1 & 2 & 3 & 3 & 2 & 1 & -1 & -2 & -3 & -3 & -2 & -1 \\
\hline & 3 & 11 & 7 & 2 & 5 & 6 & 6 & 5 & 2 & -2 & -5 & -6 & -6 & -5 & -2 \\
\hline & 2 & 10 & 6 & 3 & 6 & 9 & 9 & 6 & 3 & -3 & -6 & -9 & -9 & -6 & -3 \\
\hline & 1 & 9 & 5 & 3 & 6 & 9 & 9 & 6 & 3 & -3 & -6 & -9 & -9 & -6 & -3 \\
\hline & 12 & 8 & 4 & 2 & 5 & 6 & 6 & 5 & 2 & -2 & -5 & -6 & -6 & -5 & -2 \\
\hline & 11 & 7 & 3 & 1 & 2 & 3 & 3 & 2 & 1 & -1 & -2 & -3 & -3 & -2 & -1 \\
\hline & 10 & 6 & 2 & -1 & -2 & -3 & -3 & -2 & -1 & 1 & 2 & 3 & 3 & 2 & 1 \\
\hline & 9 & 5 & 1 & -2 & -5 & -6 & -6 & -5 & -2 & 2 & 5 & 6 & 6 & 5 & 2 \\
\hline \multirow{3}{*}{$\mathcal{R}_{\tau}$} & +3 & +2 & +1 & 1 & 2 & 3 & 4 & 5 & 6 & 7 & 8 & 9 & 10 & 11 & 12 \\
\hline & +6 & +5 & +4 & 5 & 6 & 7 & 8 & 9 & 10 & 11 & 12 & 1 & 2 & 3 & 4 \\
\hline & +9 & +8 & +7 & 9 & 10 & 11 & 12 & 1 & 2 & 3 & 4 & 5 & 6 & 7 & 8 \\
\hline
\end{tabular}

Table 4 Impact factor of torque and flux for rotation vectors of matrix convertor

\begin{tabular}{|c|c|c|c|c|c|c|c|c|c|c|c|c|c|c|}
\hline & & & & & & & Sta & flu & ect & $n_{\theta}$ & & & & \\
\hline \multirow{3}{*}{$\boldsymbol{R}_{\lambda}$} & -10 & +10 & 4 & 5 & 6 & 7 & 8 & 9 & 10 & 11 & 12 & 1 & 2 & 3 \\
\hline & -11 & +12 & 8 & 9 & 10 & 11 & 12 & 1 & 2 & 3 & 4 & 5 & 6 & 7 \\
\hline & -12 & +11 & 12 & 1 & 2 & 3 & 4 & 5 & 6 & 7 & 8 & 9 & 10 & 11 \\
\hline & 1 & 12 & -4 & -7 & -8 & -7 & -4 & 0 & 4 & 7 & 8 & 7 & 4 & 0 \\
\hline & 2 & 11 & -7 & -8 & -7 & -4 & 0 & 4 & 7 & 8 & 7 & 4 & 0 & $\overline{-4}$ \\
\hline \multirow{6}{*}{ 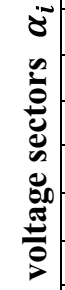 } & 3 & 10 & -8 & -7 & -4 & 0 & 4 & 7 & 8 & 7 & 4 & 0 & -4 & -7 \\
\hline & 4 & 9 & -7 & -4 & 0 & 4 & 7 & 8 & 7 & 4 & 0 & -4 & -7 & -8 \\
\hline & 5 & 8 & -4 & 0 & 4 & 7 & 8 & 7 & 4 & 0 & -4 & -7 & -8 & -7 \\
\hline & 6 & 7 & 0 & 4 & 7 & 8 & 7 & 4 & 0 & -4 & -7 & -8 & -7 & -4 \\
\hline & 7 & 6 & 4 & 7 & 8 & 7 & 4 & 0 & -4 & -7 & -8 & -7 & -4 & 0 \\
\hline & 8 & 5 & 7 & 8 & 7 & 4 & 0 & -4 & -7 & -8 & -7 & -4 & 0 & 4 \\
\hline \multirow{4}{*}{$\underline{\Xi}$} & 9 & 4 & 8 & 7 & 4 & 0 & -4 & -7 & -8 & -7 & -4 & 0 & 4 & 7 \\
\hline & 10 & 3 & 7 & 4 & 0 & -4 & -7 & -8 & -7 & -4 & 0 & 4 & 7 & 8 \\
\hline & 11 & 2 & 4 & 0 & -4 & -7 & -8 & -7 & -4 & 0 & 4 & 7 & 8 & 7 \\
\hline & 12 & 1 & 0 & -4 & -7 & -8 & -7 & -4 & 0 & 4 & 7 & 8 & 7 & 4 \\
\hline \multirow[b]{3}{*}{$\mathcal{R}_{\tau}$} & -10 & +10 & 1 & 2 & 3 & 4 & 5 & 6 & 7 & 8 & 9 & 10 & 11 & 12 \\
\hline & -11 & +11 & 5 & 6 & 7 & 8 & 9 & 10 & 11 & 12 & 1 & 2 & 3 & 4 \\
\hline & -12 & +12 & 9 & 10 & 11 & 12 & 1 & 2 & 3 & 4 & 5 & 6 & 7 & 8 \\
\hline & & & \multicolumn{12}{|c|}{ Stator flux sectors $n_{\theta}$} \\
\hline
\end{tabular}

factors, directly will effect on the change of average flux and torque parameters respectively. So, impact factors for every switching states and each evaluation function are calculated by the following relations and are indicated in Tables 3, 4, 5, 6 .

$$
\mathcal{R}_{\tau}=\operatorname{round}\left[\frac{k}{(\pi / 6)^{2}} \int_{\frac{\pi}{6}\left(n_{\alpha}-1\right)}^{\frac{\pi}{6} n_{\alpha}} \int_{\frac{\pi}{6}\left(n_{\theta}-1\right)}^{\frac{\pi}{6} n_{\theta}} \tau d \theta d \alpha\right]
$$


Table 5 Impact factor of input power factor for constant vectors of matrix convertor

\begin{tabular}{|c|c|c|c|c|c|c|c|c|c|c|c|c|c|c|c|}
\hline \multirow{12}{*}{ 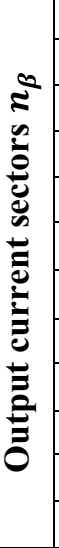 } & 8 & 4 & 12 & -6 & -9 & -9 & -6 & -3 & 3 & 6 & 9 & 9 & 6 & 3 & -3 \\
\hline & 7 & 3 & 11 & -5 & -6 & -6 & -5 & -2 & 2 & 5 & 6 & 6 & 5 & 2 & 3 \\
\hline & 6 & 2 & 10 & -2 & -3 & -3 & -2 & -1 & 1 & 2 & 3 & 3 & 2 & 1 & -1 \\
\hline & 5 & 1 & 9 & 2 & 3 & 3 & 2 & 1 & -1 & -2 & -3 & -3 & -2 & -1 & 1 \\
\hline & 4 & 12 & 8 & 5 & 6 & 6 & 5 & 2 & -2 & -5 & -6 & -6 & -5 & -2 & 2 \\
\hline & 3 & 11 & 7 & 6 & 9 & 9 & 6 & 3 & -3 & -6 & -9 & -9 & -6 & -3 & 3 \\
\hline & 2 & 10 & 6 & 6 & 9 & 9 & 6 & 3 & -3 & -6 & -9 & -9 & -6 & -3 & 3 \\
\hline & 1 & 9 & 5 & 5 & 6 & 6 & 5 & 2 & -2 & -5 & -6 & -6 & -5 & -2 & 2 \\
\hline & 12 & 8 & 4 & 2 & 3 & 3 & 2 & 1 & -1 & -2 & -3 & -3 & -2 & -1 & 1 \\
\hline & 11 & 7 & 3 & -2 & -3 & 3- & -2 & -1 & 1 & 2 & 3 & 3 & 2 & 1 & -1 \\
\hline & 10 & 6 & 2 & -5 & -6 & -6 & -5 & -2 & 2 & 5 & 6 & 6 & 5 & 2 & -2 \\
\hline & 9 & 5 & 1 & -6 & -9 & -9 & -6 & -3 & 3 & 6 & 9 & 9 & 6 & 3 & -3 \\
\hline \multirow{3}{*}{$\mathcal{R}_{\eta}$} & +3 & +2 & +1 & 1 & 2 & 3 & 4 & 5 & 6 & 7 & 8 & 9 & 10 & 11 & 12 \\
\hline & +6 & +5 & +4 & 5 & 6 & 7 & 8 & 9 & 10 & 11 & 12 & 1 & 2 & 3 & 4 \\
\hline & +9 & +8 & +7 & 9 & 10 & 11 & 12 & 1 & 2 & 3 & 4 & 5 & 6 & 7 & 8 \\
\hline
\end{tabular}

Table 6 Impact factor of input power factor for rotation vectors of matrix convertor

$\mathcal{R}_{\lambda}=\operatorname{round}\left[\frac{k}{(\pi / 6)^{2}} \int_{\frac{\pi}{6}\left(n_{\alpha}-1\right)}^{\frac{\pi}{6} n_{\alpha}} \int_{\frac{\pi}{6}\left(n_{\theta}-1\right)}^{\frac{\pi}{6} n_{\theta}} \lambda d \theta d \alpha\right]$

$\mathcal{R}_{\eta}=\operatorname{round}\left[\frac{k}{(\pi / 6)^{2}} \int_{\frac{\pi}{6}\left(n_{\alpha}-1\right)}^{\frac{\pi}{6} n_{\alpha}} \int_{\frac{\pi}{6}\left(n_{\theta}-1\right)}^{\frac{\pi}{6} n_{\theta}} \eta d \alpha d \beta\right]$

\begin{tabular}{|c|c|c|c|c|c|c|c|c|c|c|c|c|c|c|}
\hline \multirow{12}{*}{ 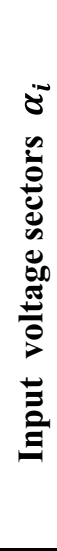 } & 1 & 12 & -4 & -7 & -8 & -7 & -4 & 0 & 4 & 7 & 8 & 7 & 4 & 0 \\
\hline & 2 & 11 & -7 & -8 & -7 & -4 & 0 & 4 & 7 & 8 & 7 & 4 & 0 & -4 \\
\hline & 3 & 10 & -8 & -7 & -4 & 0 & 4 & 7 & 8 & 7 & 4 & 0 & -4 & -7 \\
\hline & 4 & 9 & -7 & -4 & 0 & 4 & 7 & 8 & 7 & 4 & 0 & -4 & -7 & -8 \\
\hline & 5 & 8 & -4 & 0 & 4 & 7 & 8 & 7 & 4 & 0 & -4 & -7 & -8 & -7 \\
\hline & 6 & 7 & 0 & 4 & 7 & 8 & 7 & 4 & 0 & -4 & -7 & -8 & -7 & -4 \\
\hline & 7 & 6 & 4 & 7 & 8 & 7 & 4 & 0 & -4 & -7 & -8 & -7 & -4 & 0 \\
\hline & 8 & 5 & 7 & 8 & 7 & 4 & 0 & -4 & -7 & -8 & -7 & -4 & 0 & 4 \\
\hline & 9 & 4 & 8 & 7 & 4 & 0 & -4 & -7 & -8 & -7 & -4 & 0 & 4 & 7 \\
\hline & 10 & 3 & 7 & 4 & 0 & -4 & -7 & -8 & -7 & -4 & 0 & 4 & 7 & 8 \\
\hline & 11 & 2 & 4 & 0 & -4 & -7 & -8 & -7 & -4 & 0 & 4 & 7 & 8 & 7 \\
\hline & 12 & 1 & 0 & -4 & -7 & -8 & -7 & -4 & 0 & 4 & 7 & 8 & 7 & 4 \\
\hline \multirow[b]{3}{*}{$\mathcal{R}_{\tau}$} & -10 & +10 & 1 & 2 & 3 & 4 & 5 & 6 & 7 & 8 & 9 & 10 & 11 & 12 \\
\hline & -11 & +11 & 5 & 6 & 7 & 8 & 9 & 10 & 11 & 12 & 1 & 2 & 3 & 4 \\
\hline & -12 & +12 & 9 & 10 & 11 & 12 & 1 & 2 & 3 & 4 & 5 & 6 & 7 & 8 \\
\hline & & & \multicolumn{12}{|c|}{ Input voltage sectors $n_{\alpha}$} \\
\hline
\end{tabular}

$\mathcal{R}_{e}=\operatorname{round}(10 e)$

The Eq. (29) is definition of the impact factor of back emf [10].

The output of functions is rounded to the nearest integer that will be between -9 and 9 . In other words, the effect of every evaluation functions is categorized in to 18 levels.

With regards to (22), (26) and (27), the average value of torque variations stated in each cell of table is as follows: 


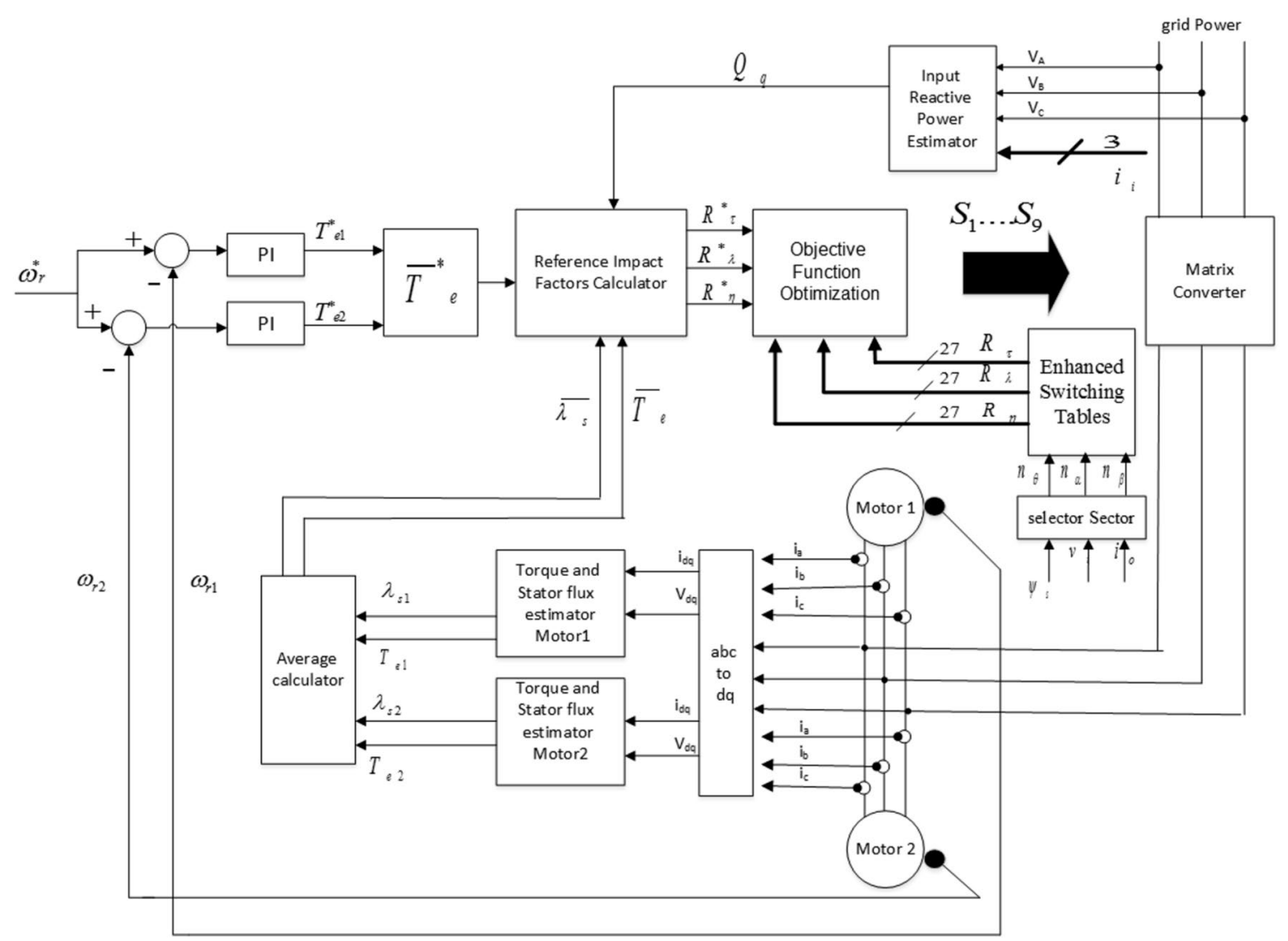

Fig. 1 Proposed DTC-SVM for dual induction motors fed by MC

$\frac{d}{d t} T_{e} \approx \operatorname{avg}\left(\frac{d}{d t} T_{e}\right) \propto \mathcal{R}_{\tau}+\mathcal{R}_{\lambda}-\mathcal{R}_{e}$

At the same way for the flux variations and input power factor variations are calculated:

$\frac{d}{d t}\left|\overrightarrow{\bar{\psi}}_{s 1}\right| \approx \operatorname{avg}\left(\frac{d}{d t}\left|\overrightarrow{\bar{\psi}}_{s 1}\right|\right) \propto \mathcal{R}_{\lambda}$

$\frac{d}{d t} Q \approx \operatorname{avg}\left(\frac{d}{d t} Q\right) \propto \mathcal{R}_{\eta}$

Finally for all 27 states, the impact factors are calculated. The impact factors of $\pm 10, \pm 11$ and \pm 12 vectors in some areas will be unaffected. In these circumstances, the effect of these factors on variations of torque, flux and input power factor in single inverter dual motor drives is considered to be zero.

\subsection{System configuration}

The proposed method consists of four main steps (Fig. 1). First, the values of stator flux and torque of motors are estimated [10] and the average values of these parameters are calculated via Eq. (13). Then input reactive power is calculated via Eq. (24). Subsequently, the reference impact values are calculated via Eqs. (33), (34) and (35) according to $\theta_{s}, \alpha_{i}$ and $\beta_{o}$ that are applied to switching table. Finally, the best switching state that leading to minimize the objective function according to Eq. (36) is selected. The values of reference impact factors to extract average torque, average flux and input reactive power are calculated as follow:

$\mathcal{R}_{\tau}^{*}=\frac{\left(\bar{T}_{e}^{*}-\bar{T}_{e}\right)}{k_{t}}+\mathcal{R}_{e}-\mathcal{R}_{\lambda}$ 
$\mathcal{R}_{\lambda}^{*}=\frac{\left(\left|\overrightarrow{\bar{\psi}}_{s}\right|^{*}-\left|\overrightarrow{\bar{\psi}}_{s}\right|\right)}{k_{\psi}}$

$\mathcal{R}_{\eta}^{*}=\frac{Q}{K_{Q}}$

where $k_{Q}, k_{\psi}$ and $k_{\tau}$ are coefficients of input reactive power, flux and positive torque respectively. The values of these parameters will have a significant impact on the variation rate of torque, flux and input power factor. The appropriate adjustment of these coefficients is also dependent on the steady state operating conditions and the variation rate of torque and flux of motors than nominal values [10].

\subsection{Objective function}

The objective function must be able to choice the best among 27 switching states that lead to the minimization of the Eq. (36). The impact factors of torque, flux and input reactive power in single inverter dual motor drives are related to each other by weighted coefficients $a_{\tau}, a_{\psi}, a_{Q}$ respectively. The values of these coefficients determine the amount of the effectiveness of impact factors in Eq. (36).

$F=a_{\tau}\left|\mathcal{R}_{\tau}^{*}-\mathcal{R}_{\tau}\right|+a_{\psi}\left|\mathcal{R}_{\lambda}^{*}-\mathcal{R}_{\lambda}\right|+a_{Q}\left|\mathcal{R}_{\eta}^{*}-\mathcal{R}_{\eta}\right|$

\section{Results}

Speed and torque are the most important controllable parameters in all motor drive methods. In this study, it was assumed that both motors are the same in terms of electrical parameters. According to the strategy used in this research, the drive system consists of two motors, was modeled like a single motor drive system. According to the reviewed articles, the problem of these systems occurs in situations where there is an imbalance in the load of the motors. Under this condition, and according to the relationships in the DTC method, each motor will need a different voltage vector, which in turn leads to differences in motor speeds, and in theory, motors speed may not follow the reference value. Therefore, the focus of the research is on showing the efficiency of the proposed method in unbalanced load conditions. Of course, the results were examined under normal conditions too. Relationships 1 to 5 show the effect of the selected voltage vector on the changes in the magnetic flux of the motors stator. If there are more vectors in the 360-degree space, the vector space will be more continuous and creating the conditions that the changes in magnetic flux are also small. Therefore, the practical results of using 27 matrix converter voltage vectors in DTC-SVM method leads to a decrease in magnetic flux ripples. According to the relationship between stator flux and motor speed, the proposed method leads to less fluctuations in motors speed and torque, which has been investigated in the simulation results.

The proposed method was compared with the conventional DTC via some numerical simulations in order to study the steady-state and dynamic performances. The machines under investigation were $200 \mathrm{HP}, 4$ poles, 460 $\mathrm{V}_{\mathrm{L}}$, and $60 \mathrm{~Hz}$ squirrel cage induction motors where stator resistance is $0.0148 \Omega$, rotor resistance is $0.0092 \Omega$, leakage inductance of stator is $0.003 \mathrm{H}$, leakage inductance of rotor is $0.003 \mathrm{H}$ and magnetizing inductance of stator is $0.01 \mathrm{H}$.

\subsection{Unbalanced load test}

The conventional [19] and proposed methods were subjected to the unbalanced load conditions. The speeds of the motors were set at $800 \mathrm{rpm}$, and both motors were started under no-load condition. After $1.2 \mathrm{~s}$, torque values of 100 and $200 \mathrm{Nm}$ were applied to the motor 1 and motor 2, respectively. The simulation results are presented in Figs. 2 and 3. Figures 4 and 5 show more details about the speed curves. As can be seen, in both methods, both motors followed the torque command. Furthermore, fluctuations can be observed in the torque curve for $0.2 \mathrm{~s}$ after step change in the load occurred. In the proposed method, these fluctuations occurred in the motor subjected to the lower load, while in the conventional approach the fluctuations occurred in the motor under higher load. It is also clear in Figs. 4 and 5 that in the proposed method, there are less oscilations in motor speed compared with the conventinoal approach. According to Figs. 2 and 3, torque ripple reduced significantly in the proposed approach.

\subsection{Change in speed step under unbalanced load condition}

An investigation was made into the effect of changes in the reference speed on the transient and steady-state performance in the proposed DTC method. Both motors were started under no-load condition, but the load of motor 1 was changed to $400 \mathrm{Nm}$ after $3 \mathrm{~s}$. When the reference speed was changed from 1500 to $500 \mathrm{rpm},-500 \mathrm{rpm}$ and $-1500 \mathrm{rpm}$ both motors followed the speed command closely. In this section, torque changes and motor speeds in braking mode are also examined. When the speed is negative, the motor's transient torque is visible. In this case, the motor with low load will have more 

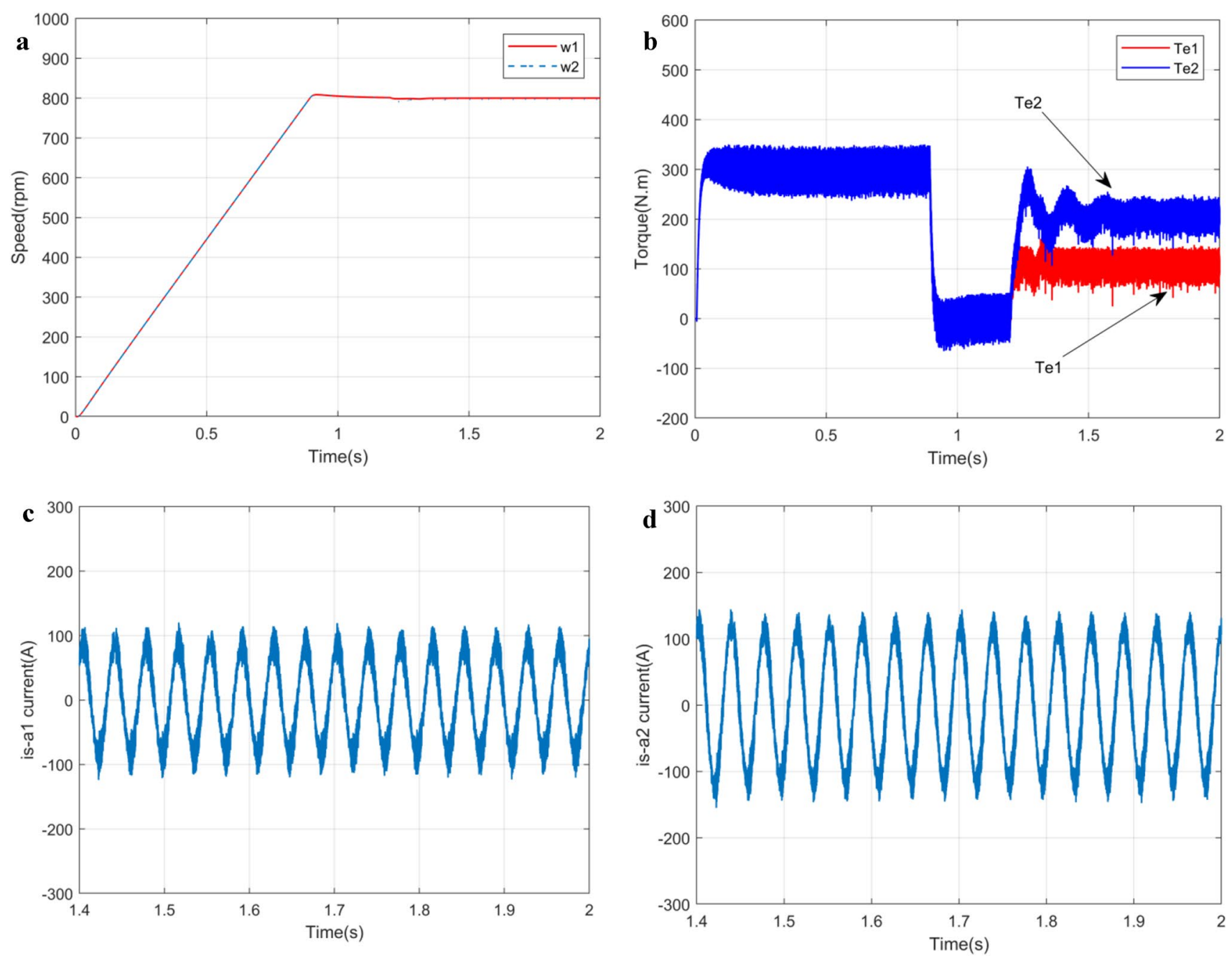

Fig. 2 Unbalanced load condition in conventional DTC: a Speed of motors; $\mathbf{b}$ Torque of motor; $\mathbf{c}$ current of motor 1 ; $\mathbf{d}$ current of motor 2

fluctuations in torque and current. According to the equations extracted in the previous section, these fluctuations are predictable for low-load motors. Figure 6 illustrates the characteristics of both motors in this condition. Fluctuations can be seen in the torque curve of motor 2 for $0.4 \mathrm{~s}$, but fluctuations were damped in the steady-state condition.

\subsection{Dynamic performance during a change in torque command}

This subsection discusses the ability of the proposed method to generate electrical power when motors brake.
According to Fig. 7, torque was changed from +400 to $-400 \mathrm{Nm}$, with speed being set at $600 \mathrm{rpm}$. The speed and torque followed the reference values. As can be seen in Fig. 8 , sinusoidal voltage is in phase with the corresponding current at the input side of matrix convertor, and this confirms the validity of the propounded DTC to operate under unit input power factor. When the torque command changes, the direction of motor current changes.According to Fig. 8, the phase angle difference between input current and corresponding voltage is about $\pi$ radian, indicating that the machines now generate electrical power. In this case, motors speed is more than the reference speed because slip is more than 1 . 

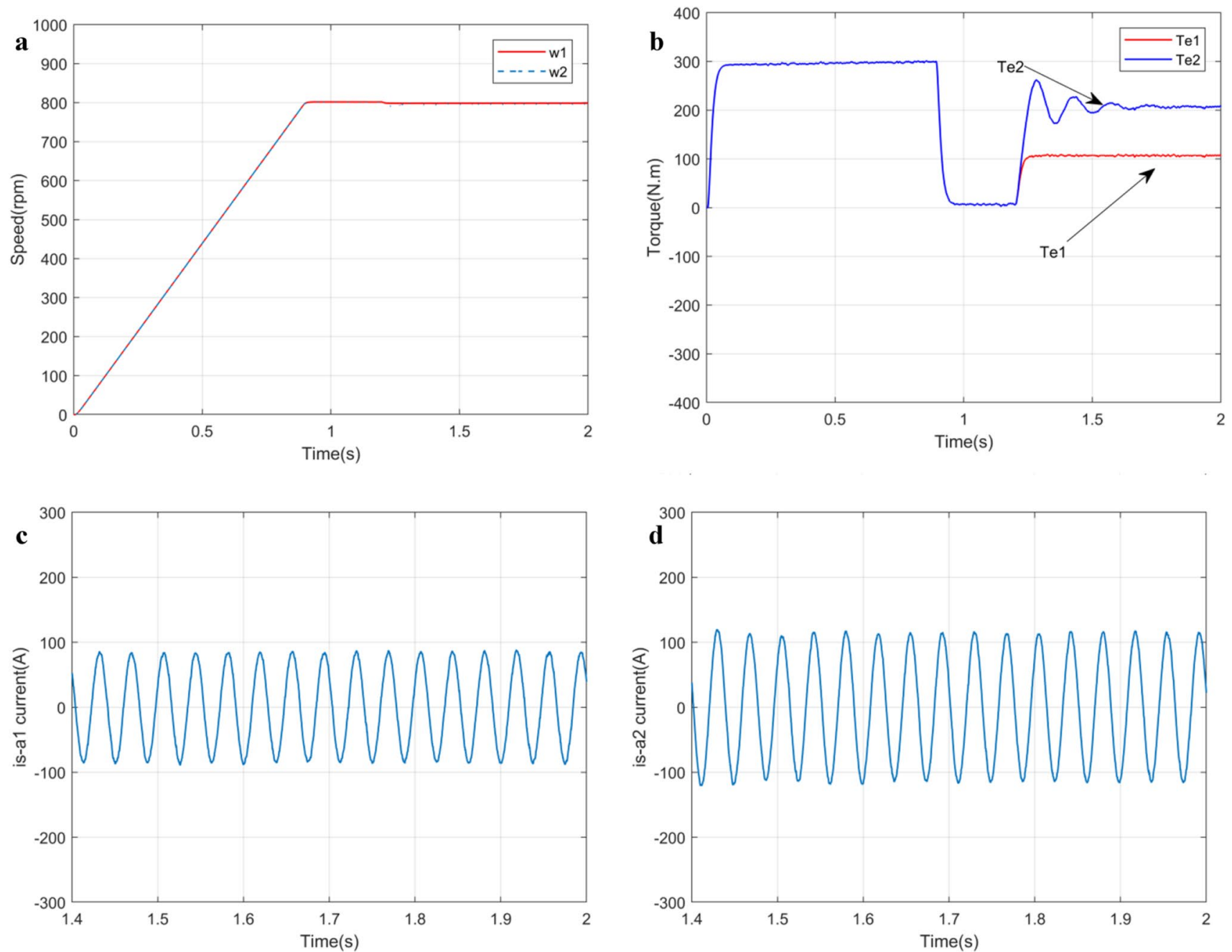

Fig. 3 Unbalanced load condition in the proposed DTC: a speed of motors; $\mathbf{b}$ Torque of motors; $\mathbf{c}$ Current of motor 1; $\mathbf{d}$ Current of motor 2

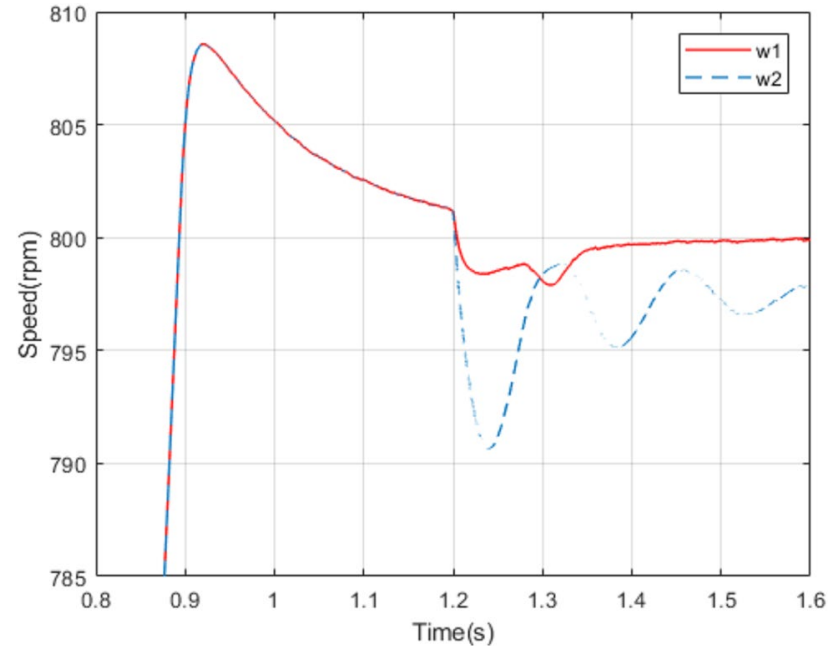

Fig. 4 Speed of motors under unbalanced load condition in conventional DTC

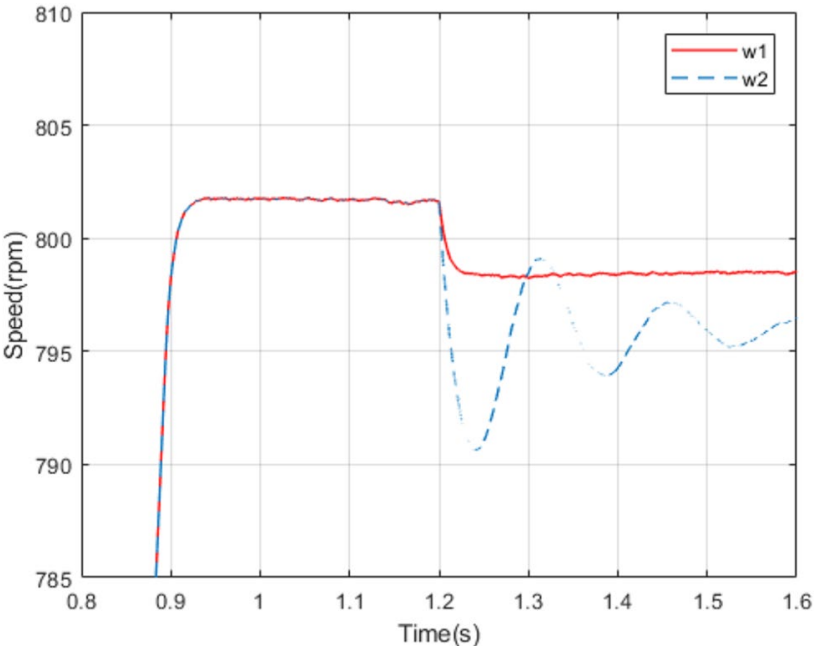

Fig. 5 Speed of motors under unbalanced load condition in the proposed DTC 

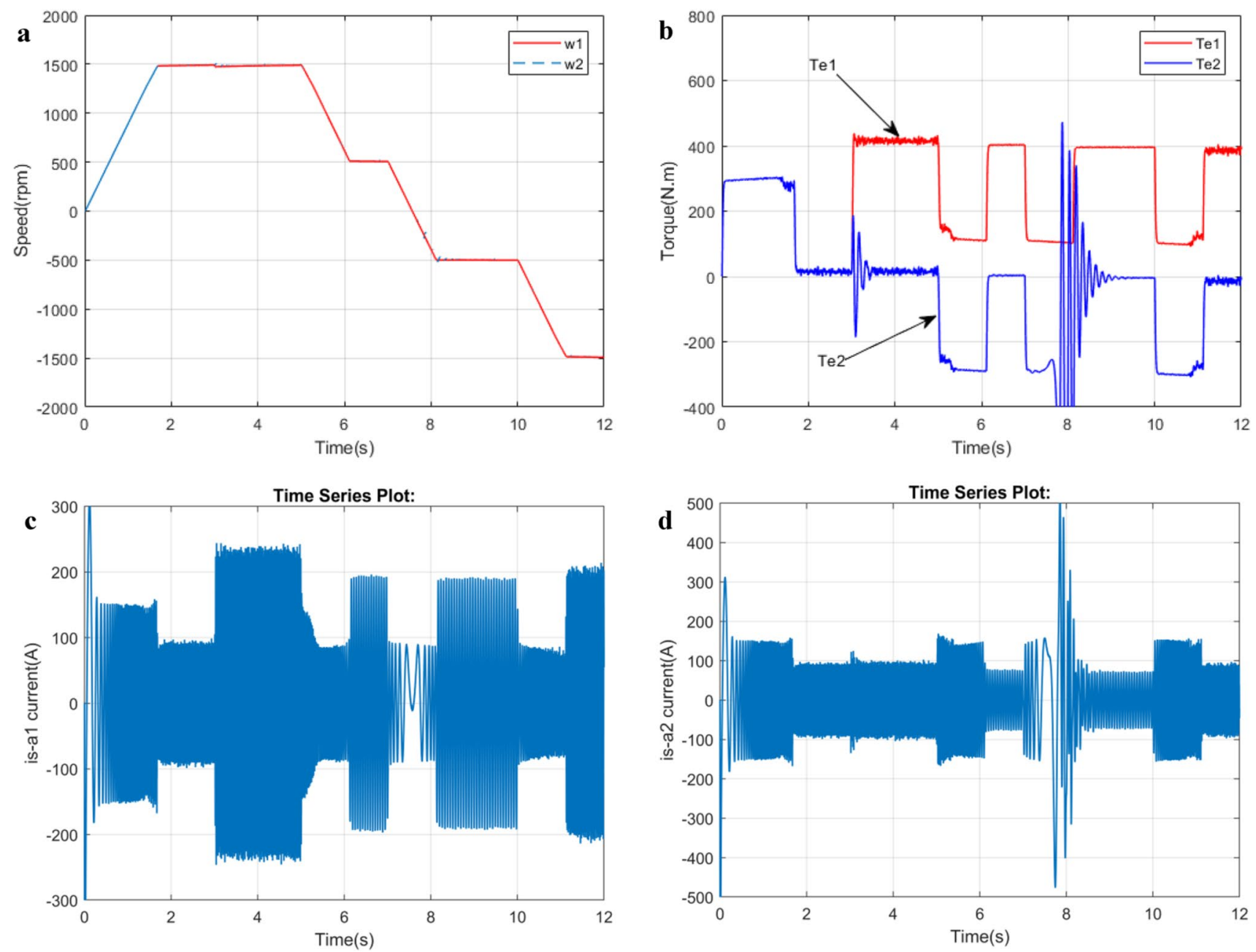

Fig. 6 Speed step command under unbalanced load condition in the proposed DTC: a motors speed; $\mathbf{b}$ motors torque; c stator current of motor 1 ; $\mathbf{d}$ stator current of motor 2

\section{Conclusions}

In this study a new DTC control method based on mean control pattern for dual identical induction motors fed by a matrix convertor proposed. The main question of the research was whether the speed of two motors in unbalanced loads conditions can be controlled by a single convertor? Also, the effect of the proposed method on the current and motor torque ripple was another question. This method without adding complexity to DTC, effectively uses all matrix convertor switching states and combines the advantages of matrix convertor with the benefits of DTC for use in an single inverter dual motor drives system and hysteresis blocks are replaced with the PI controller.

The effect of each matrix convertor switching states on the change rates of the torque, flux and input power factor of single inverter dual motor drives systems was evaluated. Finally, by using an objective function and based on the switching tables the optimal voltage vector selected. The performance of proposed method has been tested by simulations and The results showed a significant improvement in torque speed and fluctuations compared to the basic method. Furthermore, the proposed method provides a safe condition for motors to operate during the regenerative braking condition.

According to the results of the present study, it is suggested that the Master-Slave strategy be used to simultaneous control of the two motors with a single convertor and the results of this strategy be compared with the proposed method. It is also suggested that the proposed strategy in this study be evaluated with the use of a fiveleg inverter instead of a matrix convertor. Practical experiments to compare with simulations results will be effective in improving the proposed method. 

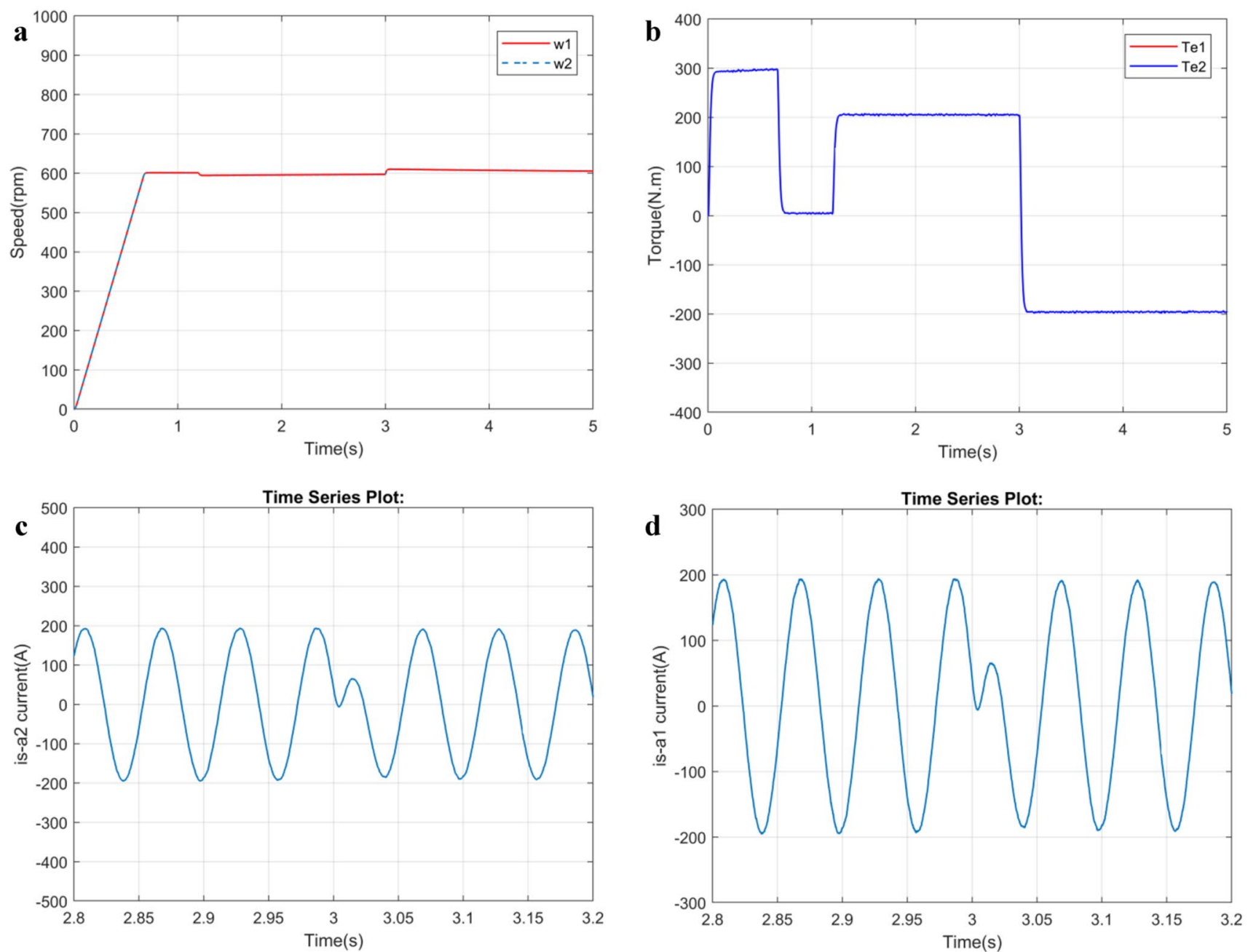

Fig. 7 Torque step command from $+400 \mathrm{Nm}$ to $-400 \mathrm{Nm}$ at $600 \mathrm{rpm}$ in the proposed DTC: a motor speed; $\mathbf{b}$ motor torque; $\mathbf{c}$ stator current of Motor 1; d stator current of Motor 2

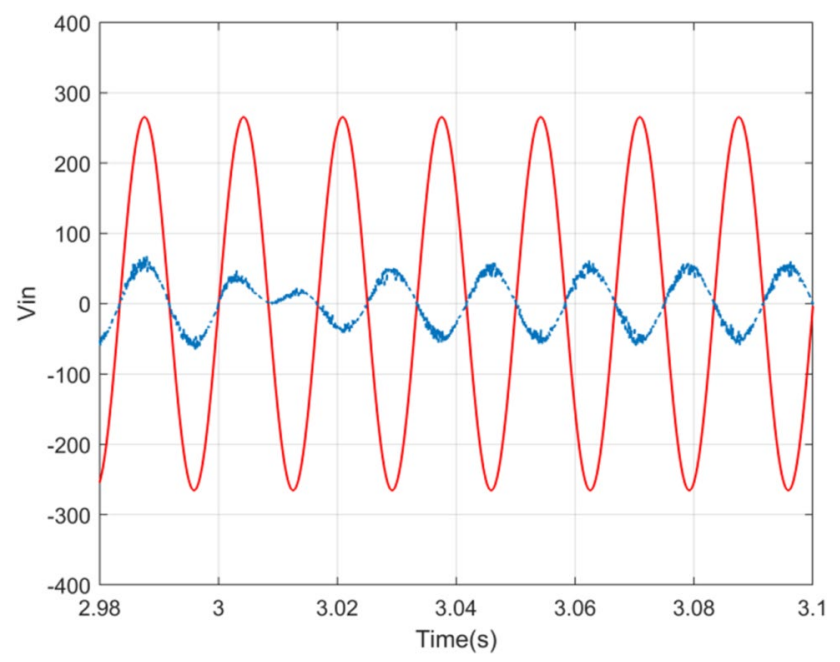

Fig. 8 Input voltage and input current waveform at $600 \mathrm{rpm}$ during torque step command in the proposed DTC

\section{Declarations}

Conflict of interest The authors declare that they have no competing interests.

Open Access This article is licensed under a Creative Commons Attribution 4.0 International License, which permits use, sharing, adaptation, distribution and reproduction in any medium or format, as long as you give appropriate credit to the original author(s) and the source, provide a link to the Creative Commons licence, and indicate if changes were made. The images or other third party material in this article are included in the article's Creative Commons licence, unless indicated otherwise in a credit line to the material. If material is not included in the article's Creative Commons licence and your intended use is not permitted by statutory regulation or exceeds the permitted use, you will need to obtain permission directly from the copyright holder. To view a copy of this licence, visit http://creativecommons. org/licenses/by/4.0/. 


\section{References}

1. Joshi BM, Chandorkar MC (2014) Vector control of two-motor single-inverter induction machine drives. Electric Power Component Syst 42:1158-1171

2. Jones M, Levi E, Iqbal A (2005) Vector control of a five-phase series-connected two-motor drive using synchronous current controllers. Electric Power Component Syst 33:411-430

3. Xu F, Shi L, Li Y (2013) The weighted vector control of speedirrelevant dual induction motors fed by the single inverter. IEEE Trans Power Electr 12:5665-5672

4. Mohktari $\mathrm{H}$, Alizadeh A (2007) A new multi-machine control system based on Direct Torque Control algorithm. In: IEEE 2007 international conference on power electronics. IEEE, Daegu, Korea (South), pp 1103-1108

5. Joshi BM, Chandorkar MC (2011) Effect of machine asymmetry on a two-machine direct torque controlled induction motor drive. In: EPE 2011 Proceedings of 14th European conference on power electronics and applications. IEEE, Birmingham, UK, pp 1-10

6. Ninad NA, Lopes L (2014) Per-phase vector control strategy for a four-leg voltage source inverter operating with highly unbalanced loads in stand-alone hybrid systems. Int J Electr Power 55:449-459

7. Nguyen TD, Lee HH (2016) Development of a three-to-fivephase indirect matrix converter with carrier-based PWM based on space-vector modulation analysis. IEEE Trans Ind Electron 63:13-24

8. Lim CS, Rahim NA, Hew WP, Levi E (2013) Model predictive control of a two-motor drive with five-leg-inverter supply. IEEE Trans Ind Electron 60:54-65

9. Matsuse K, Kezuka N, Oka K (2011) Characteristics of independent two induction motor drives fed by a four-leg inverter. IEEE Trans Ind Appl 47:2125-2134

10. Xia C, Zhao J (2014) A novel direct torque and flux control method of matrix converter fed PMSM drives. IEEE Trans Power Electron 29:5417-5430

11. You K, Xiao D, Rahman MF, Uddin MN (2014) Applying reduced general direct space vector modulation approach of $A C-A C$ matrix converter theory to achieve direct power factor controlled three-phase AC-DC matrix rectifier. IEEE Trans Ind Appl 50:2243-2257

12. Friedli T, Kolar JW (2012) Milestones in matrix converter research. IEEJ J Ind Appl 1:2-14

13. Friedli T, Kolar JW (2010) Comprehensive comparison of three-phase AC-AC matrix converter and voltage DC-Link back-to-back converter systems. In: IEEE 2010 international power electronics conference (IPEC). IEEE, Sapporo, Japan, pp 2789-2798

14. Matsuse K, Kawai H, Kouno Y, Oikawa J (2004) Characteristics of speed sensor less vector controlled dual induction motor drive connected in parallel fed by a single inverter. IEEE Trans Ind Appl 40:153-1561

15. Matsuse K, Kouno Y, Kawai H, Yokomizo S (2002) A speed-sensorless vector control method of parallel-connected dual induction motor fed by a single inverter. IEEE Trans Ind Appl 38:1566-1571

16. Xu F, Shi L, Wang K, Li Y (2014) A control strategy of dual induction motors fed by single inverter for traction system. In: IEEE transportation electrification conference and expo, Asia-Pacific (ITEC Asia-Pacific). IEEE, Beijing, China, pp 1-6

17. Gunabalan R, Sanjeevikumar P, Blaabjerg F, Ojo O, Subbiah V (2015) Analysis and implementation of parallel connected twoinduction motor single-inverter drive by direct vector control for industrial application. IEEE Trans Power Electr 30:6472-6475

18. Sebtahmadi SS, Pirasteh H, Mekhleif S (2014) A 12-sector space vector switching scheme for performance improvement of matrix converter based DTC of IM drive. IEEE Trans Power Electron 30:3804-3817

19. Maurice F, Ngoc LN, Ana L (2013) Direct torque control-a solution for mono inverter-dual parallel PMSM system. In: 21st mediterranean conference on control and automation.IEEE, Platanias-Chania, Crete - Greece, pp 1477-1483

20. Xiao D, Rahman MF (2011) A novel hysteresis direct torque control for matrix converter drives. EPE J 21:40-48

21. Hamouda M, Blanchette HF, Al-Haddad K (2015) Indirect matrix converters enhanced commutation method. IEEE Trans Ind Electron 62:671-679

22. Casadei D, Profumo F, Serra G, Tani A (2002) FOC and DTC: two viable schemes for induction motors torque control. IEEE Trans Power Electr 17:779-787

23. Lee KB, Blaabjerg F (2008) Sensorless DTC-SVM for induction motor driven by a matrix converter using a parameter estimation strategy. IEEE Trans Ind Electron 55:512-521

24. Casadei D, Rossi C (2000) Inverter state selection by neural network in DTC induction motor drives. In: Proceedings of SPEEDAM'00 Conference, Ischia, Italy, pp C413-C418

25. Grabowski PZ, Blaabjerg F (1998) Direct torque neuro-fuzzy control of induction motor drive. DSP implementation. In: Conference Rec. IECON'98, Aachen, Germany, pp 657-661

Publisher's Note Springer Nature remains neutral with regard to jurisdictional claims in published maps and institutional affiliations. 